\title{
Multidimensional Relative Poverty of Farmers in Tibetan Areas - Based on a Data Analysis on Micro Surveys
}

\author{
Shilian Zhu* \\ School of Economics, Sichuan Agricultural University, Chengdu 611100, Sichuan Province, China \\ *Corresponding author: Shilian Zhu, zs119980730@163.com
}

\begin{abstract}
In 2020, the issue of absolute poverty has been solved, and China is building a well-off society in an all-round way. The issue of relative poverty is an important content of poverty reduction. Based on a survey data from Danba County in October 2020, this paper uses the AF method to calculate the incidence of multidimensional poverty and the multidimensional poverty index. The results showed that $44.65 \%$ of the farmers have multidimensional deprivation of any three indicators of relative poverty, and $2.79 \%$ of the farmers have serious multidimensional deprivation; the incidence of one-dimensional poverty in terms of "educational level index of head of household," "per capita non-transfer income of households in 2019," and "per capita household income in 2019 " is the highest; at the same time, the contribution rate of the three indicators to the multidimensional poverty index is also higher than other indicators. Therefore, several suggestions have been put forward to alleviate the multidimensional relative poverty in the region from the aspects of industry development and education.
\end{abstract}

Keywords: Relative poverty; Multidimensional poverty; AF method; Poverty decomposition

Publication date: December 2021; Online publication: December 31, 2021

\section{Introduction}

The year 2020 is the final term of the decisive battle against poverty. Under current standards, as of the end of 2019 , the national poverty incidence rate has dropped to $0.6 \%{ }^{[1]}$. As one of the deep poverty counties in Tibet related areas, Danba County has eliminated absolute poverty, but its natural geography is fragile, and its economic development is limited. Therefore, it is urgent to explore how to consolidate the achievements of poverty alleviation and alleviate the relative poverty in this area from multidimensional levels.

The academic research on relative poverty mainly focuses on the concept, standards, and causes of relative poverty. The concept of relative poverty was introduced by Townsend ${ }^{[2]}$. Wang Sangui and Zeng Xiaoxi believe that the relative poverty standard can be adjusted ${ }^{[3]}$. Zhang Chuanzhou believes that relative poverty is mainly affected by external factors ${ }^{[4]}$. Relative poverty and multidimensional poverty coexist. After the 1980s, Sen proposed the theory of "feasible ability" to explain multidimensional poverty ${ }^{[5]}$. Wang Xiaolin and Feng Hexia constructed a multidimensional conceptual framework of relative poverty standard based on the theory of feasible ability ${ }^{[6]}$. Zhang Haixia and other researchers used the AF method to measure the multidimensional poverty of farmers and herdsmen in Gansu Tibetan areas ${ }^{[7]}$. Deng Dasong and other researchers studied the impact of targeted poverty alleviation policies and migrant workers on the multidimensional poverty of farmers ${ }^{[8]}$.

Based on this, this article intends to start from the perspective of relative poverty, introduce multidimensional poverty indicators, and use the AF method to analyze the multidimensional relative poverty status of farmers in Danba County, in order to provide decision-making bases for Danba County's 
relative poverty governance, so as to better alleviate its relative poverty.

\section{Data source and measurement methods}

\subsection{Data source}

The data source of this paper is the survey data collected by a research group in Danba County in October 2020. The survey adopted the random sampling method, selected 235 households in 7 towns of Danba County, used the question-and-answer questionnaire interview method to collect the data, eliminated invalid questionnaires, and finally obtained 215 valid questionnaires, with an effective rate of $91.5 \%$.

\subsection{Measurement methods}

This paper uses the AF method to analyze the multidimensional relative poverty of farmers in Danba County.

\subsubsection{Determination and value of poverty dimensions and indicators}

Based on existing literatures, this paper has selected five dimensions (income, education, health, employment, and information acquisition) and seven indicators to identify poverty.

Let $X=\left[x_{i j}\right]$ be a matrix of order $n * d$, which represents the state of $n$ individuals under $d$ indexes; $x i j$ represents the state of individual $i$ under index $j, z_{j}\left(z_{j}>0\right)$ represents the deprivation critical value of index $\mathrm{j}$, and $\mathrm{Z}$ represents the deprivation critical value of specific index.

\subsubsection{Individual deprivation and weight setting under each index}

The deprivation matrix $\mathrm{g} 0=\left[\mathrm{g}_{\mathrm{ij}}^{0}\right]$ is defined. When $\mathrm{x}_{\mathrm{ij}}<\mathrm{z}_{\mathrm{ij}}, \mathrm{g}_{\mathrm{ij}}^{0}=1$, indicating that individual $\mathrm{i}$ is deprived under index $\mathrm{j}$; when $\mathrm{x}_{\mathrm{ij}}>=\mathrm{z}_{\mathrm{ij}}, \mathrm{g}^{0} \mathrm{ij}=0$, indicating that individual $\mathrm{i}$ is not deprived under index $\mathrm{j}$. Weight $\mathrm{W}_{\mathrm{j}}$ is given to each index, and $\mathrm{g}_{\mathrm{ij}}^{0} \times \mathrm{W}_{\mathrm{j}}$ represents the deprivation value of individual $\mathrm{i}$ in index $\mathrm{j}$.

Let $\mathrm{c}_{\mathrm{i}}$ be the sum of deprivation values of individual $\mathrm{i}$ on all indexes,

$$
c_{i}=\sum_{j=1}^{m} w_{j} g_{i j}^{0}
$$

\subsubsection{Judging whether the individual is in multidimensional relative poverty}

Let $\mathrm{k}$ be the critical value of the poverty dimension, and based on the $\mathrm{k}$ value, the multidimensional poverty of individuals is determined.

$$
c_{i}(k)=\left\{\begin{array}{l}
\sum_{j=1}^{d} W_{j} g^{0}{ }_{i j}, c_{i} \geq k \\
0, c_{i}<k
\end{array}\right.
$$

When $\mathrm{c}_{\mathrm{i}}>=\mathrm{k}, \mathrm{c}_{\mathrm{i}}(\mathrm{k})=1$, indicating that individual $\mathrm{i}$ is in multidimensional relative poverty; when $\mathrm{c}_{\mathrm{i}}<$ $\mathrm{k}, \mathrm{c}_{\mathrm{i}}(\mathrm{k})=0$, indicating that individual $\mathrm{i}$ is in non-multidimensional relative poverty.

\subsubsection{Measuring the multidimensional poverty index (MPI)}

After judging the multidimensional relative poverty status of individuals, the multidimensional poverty 
index (MPI) can be obtained by calculating the incidence of multidimensional relative poverty and the average deprivation share.

The formula to calculate multidimensional poverty index (MPI) is as follows:

$$
M P I=H A=1 / n \sum_{i=1}^{n} c_{i}(k)
$$

In the formula, $\mathrm{H}$ is the incidence rate of multidimensional poverty, $\mathrm{H}=\mathrm{q} / \mathrm{n}, \mathrm{q}$ is the total number of individuals judged as multidimensional poverty subjects when the critical value of the poverty dimension is $\mathrm{k}, \mathrm{n}$ is the total number of objects, and $\mathrm{A}$ is the average deprivation share, which is the weighted average of the deprivation scores of the multidimensional poverty population.

$$
A=1 / q \sum_{i=1}^{n} c_{i}(k)
$$

\subsubsection{Calculating the poverty contribution rate of each index}

The multidimensional poverty index can be decomposed according to different standards. This paper calculates the contribution rate of each index to the multidimensional poverty index according to the index decomposition.

According to the MPI obtained from the above formula, the contribution rate of poverty of each dimension is calculated.

$$
M P I_{\mathrm{j}}=\left[\left(q_{\mathrm{j}} / n\right) \times w_{j}\right] / M P I
$$

In the formula, $\mathrm{MPI}_{\mathrm{j}}$ represents the contribution rate of index $\mathrm{j}$ to the multidimensional poverty index, and $\mathrm{q}_{\mathrm{j}}$ represents the total number of multidimensional relative poverty individuals deprived in index $\mathrm{j}$.

\section{Multidimensional relative poverty analysis of farmers}

\subsection{Poverty dimension and index selection}

As there is no unified standard for the selection of multidimensional poverty dimensions and indicators, this paper has selected five dimensions and seven indicators (Table 1) from two aspects - economy and development - with reference to relevant literature. At the same time, this paper has chosen the equal weight method that is widely used in existing research. 
Table 1. Definition of poverty dimensions, indicators, and deprivation threshold

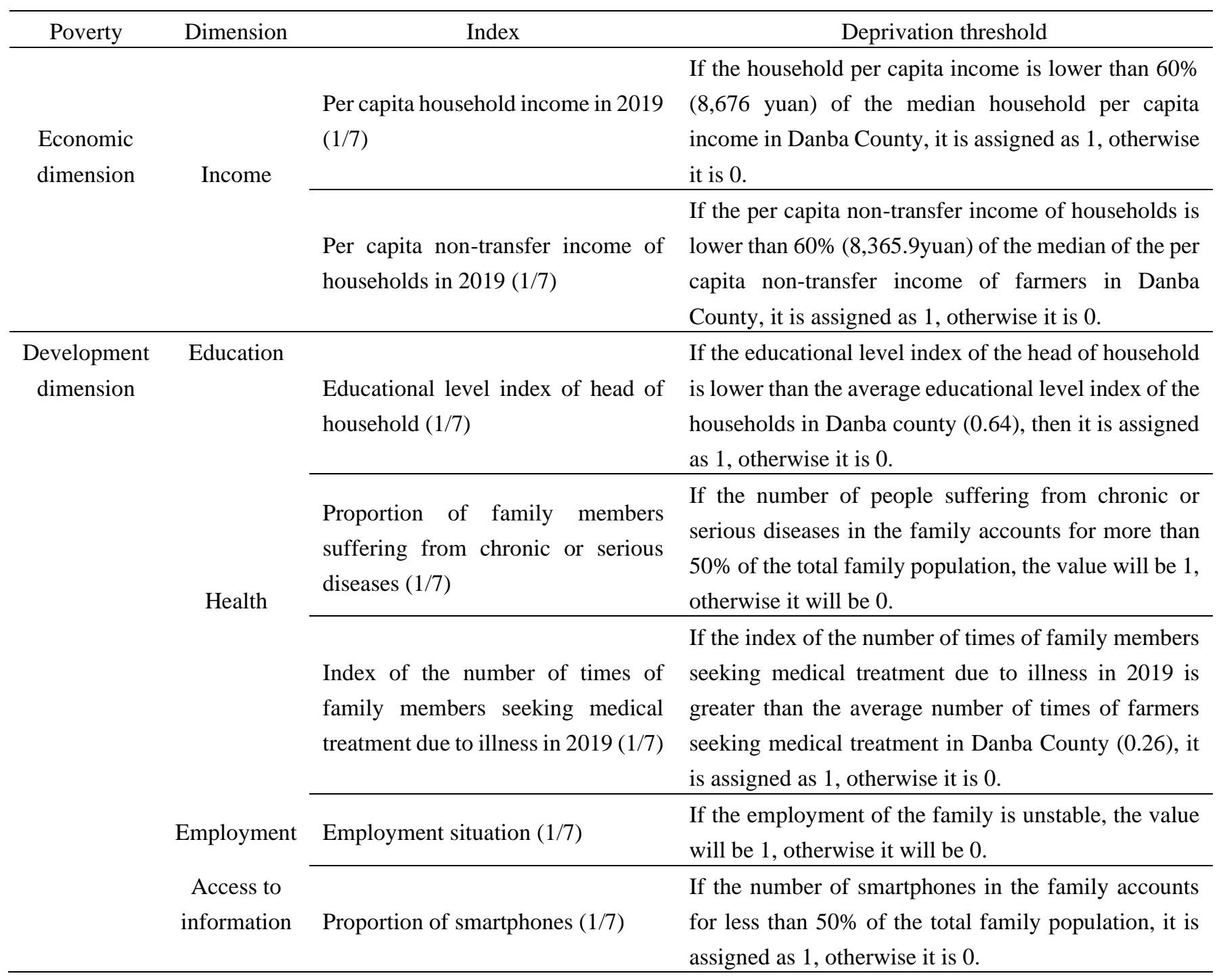

\subsection{Results of one-dimensional relative poverty estimation of rural households}

Table 2 reports the one-dimensional relative poverty incidence of seven indicators under five deprivation dimensions in Danba County. It can be seen from Table 2 that the problem of relative poverty of farmers is more prominent in the dimensions of income and education. Among them, the index with the highest incidence of poverty is "education level index of head of household," reaching $64.70 \%$; followed by "per capita non-transfer income of households in 2019," reaching 54.40\%; the third is the "per capita household income in 2019 ," reaching $46.00 \%$. 
Table 2. Incidence rate of one-dimensional relative poverty of rural households in Danba County in 2019 $1 \%$

\begin{tabular}{|c|c|c|c|c|c|}
\hline Poverty & Dimension & Index & Population & $\begin{array}{l}\text { Registered } \\
\text { households }\end{array}$ & $\begin{array}{c}\text { Non-registered } \\
\text { households }\end{array}$ \\
\hline \multirow[t]{2}{*}{$\begin{array}{l}\text { Economic } \\
\text { dimension }\end{array}$} & \multirow[t]{2}{*}{ Income } & $\begin{array}{l}\text { Per capita household income in } \\
2019\end{array}$ & 46.00 & 48.00 & 32.10 \\
\hline & & $\begin{array}{l}\text { Per capita non-transfer income } \\
\text { of households in } 2019\end{array}$ & 54.40 & 58.30 & 28.60 \\
\hline \multirow[t]{6}{*}{$\begin{array}{l}\text { Development } \\
\text { dimension }\end{array}$} & Education & $\begin{array}{l}\text { Educational level index of head } \\
\text { of household }\end{array}$ & 64.70 & 69.00 & 35.70 \\
\hline & \multirow{3}{*}{ Health } & $\begin{array}{l}\text { Proportion of family members } \\
\text { suffering from chronic or serious }\end{array}$ & 11.20 & 10.70 & 14.30 \\
\hline & & diseases & & & \\
\hline & & $\begin{array}{l}\text { Index of the number of times of } \\
\text { family members seeking medical } \\
\text { treatment due to illness in } 2019\end{array}$ & 14.90 & 12.80 & 28.60 \\
\hline & Employment & Employment situation & 19.10 & 19.30 & 17.90 \\
\hline & $\begin{array}{l}\text { Access to } \\
\text { information }\end{array}$ & Proportion of smartphones & 22.30 & 20.90 & 32.10 \\
\hline
\end{tabular}

\subsection{Multidimensional relative poverty estimation of rural households}

Table 3 reports the incidence of multidimensional relative poverty of rural households. When $\mathrm{k}=3$, more than $40 \%$ of farmers have multidimensional poverty; when $\mathrm{k}=6$, the incidence of multidimensional poverty is $2.79 \%$, which reflects a serious multidimensional deprivation state. When $\mathrm{k}=7$, the incidence of multidimensional poverty is 0 , which indicates that extreme poverty does not exist in Danba County.

Table 4 reports the average deprivation share of farmers' relative poverty, which is gradually increasing with the increase of $\mathrm{k}$. Table 5 reports the multidimensional poverty index in regard to the relative poverty of farmers. When $\mathrm{k}<5$, the multidimensional poverty index of registered households is higher than that of non-registered households; when $\mathrm{k}>=5$, the multidimensional poverty index of nonregistered households is higher than that of registered households. This shows that non-filing card users mainly suffer from severe multidimensional deprivation.

Table 3. Incidence of multidimensional relative poverty of rural households in Danba County in 2019

\begin{tabular}{cccc}
\hline \multirow{2}{*}{$\mathrm{k}$} & Incidence & \multicolumn{2}{c}{ Poverty $(\mathrm{H})$} \\
\cline { 2 - 4 } & Population & Registered households & Non-registered households \\
\hline 1 & 92.56 & 94.12 & 82.14 \\
2 & 66.51 & 67.91 & 57.14 \\
3 & 44.65 & 48.13 & 21.43 \\
4 & 18.14 & 18.72 & 14.29 \\
5 & 7.91 & 7.50 & 10.71 \\
6 & 2.79 & 2.70 & 3.57 \\
\hline
\end{tabular}


Table 4. Average deprivation share of relative poverty among farmers in Danba County in 2019

\begin{tabular}{cccc}
\hline $\mathrm{k}$ & \multicolumn{3}{c}{ Average deprivation share (A) } \\
\hline & Population & Registered households & Non-registered households \\
\hline 1 & 0.36 & 0.36 & 0.33 \\
2 & 0.44 & 0.45 & 0.41 \\
3 & 0.52 & 0.51 & 0.62 \\
4 & 0.66 & 0.65 & 0.71 \\
5 & 0.76 & 0.77 & 0.76 \\
6 & 0.86 & 0.86 & 0.86 \\
\hline
\end{tabular}

Table 5. Multidimensional poverty index of farmers in Danba County in 2019

\begin{tabular}{cccc}
\hline $\mathrm{k}$ & \multicolumn{3}{c}{ Multidimensional poverty index (MPI) } \\
\hline & Population & Registered households & Non-registered households \\
\hline 1 & 0.33 & 0.34 & 0.27 \\
2 & 0.30 & 0.30 & 0.23 \\
3 & 0.23 & 0.25 & 0.13 \\
4 & 0.12 & 0.12 & 0.10 \\
5 & 0.06 & 0.06 & 0.08 \\
6 & 0.02 & 0.02 & 0.03 \\
\hline
\end{tabular}

\section{Conclusion and enlightenment}

This paper uses the AF method to measure the multidimensional deprivation of 235 households in Danba County. The results showed that on the whole, $44.65 \%$ of the farmers have multidimensional relative poverty of any three indicators, and $2.79 \%$ of the farmers have serious multidimensional deprivation. Second, in terms of sub-indicators, three indicators ("education level index of head of household," "transfer income per capita of households in 2019," and the "per capita income of households in 2019") have the highest incidence of one-dimensional poverty.

Therefore, with China entering the post-poverty alleviation era in 2020, the relative poverty alleviation in Danba County should focus on improving its local education poverty alleviation efforts and the education infrastructure as well as fundamentally curb the intergenerational transmission of education poverty. Second, the government should guide farmers to develop the tourism industry according to local conditions and improve their income levels, so as to narrow the income gap and reduce income inequality.

\section{Funding}

This research was supported by the Key Project of Sichuan Provincial Key Research Base of Philosophy and Social Sciences - Innovative Research on Sichuan Precision Poverty Alleviation Mechanism (Project Number: CR1502).

\section{Disclosure statement}

The author declares that there is no conflict of interest. 


\section{Author contributions}

The author used the survey data of Danba County as well as the A-F method to analyze the multidimensional relative poverty status of farmers in Danba County and wrote the paper.

\section{References}

[1] Director of the Household Survey Office of the National Bureau of Statistics, 2019, Fang Xiaodan: The Country's Rural Poverty Population Will Be Reduced by 11.09 Million in 2019. National Bureau of Statistics. http://www.stats.gov.cn/tjsj/sjjd/202001/t20200123_1724700.html

[2] Townsend P, 1979, Poverty in the United Kingdom: A Survey of Household Resources and Standards of Living, University of California Press, Berkeley.

[3] Wang S, Zeng X, 2018, Preliminary Study on Poverty After 2020. Journal of Hohai University (Philosophy and Social Sciences), 20(02): 7-13, 89.

[4] Zhang C, 2020, Connotation, Measurement and Countermeasures of Relative Poverty. Journal of Northwest University for Nationalities (Philosophy and Social Sciences Edition), 2020(02): 112-119.

[5] Amartya S, 2001, Poverty and Famine [Wang Y, Wang W, Trans.], Commercial Press, Beijing.

[6] Wang X, Feng H, 2020, Multi-Dimensional Relative Poverty Standard of China After 2020: International Experience and Policy Orientation. China's Rural Economy, 2020(03): 2-21.

[7] Zhang H, Yang F, Zhuang T, 2018, Study on Multidimensional Poverty Measurement of farmers and herdsmen in Tibetan areas - Taking Gansu Tibetan areas as an Example. Journal of Sichuan Agricultural University, 36(04): 555-561, 568.

[8] Deng D, Zhong Y, Yang J, 2020, Analysis on the Impact Mechanism of Targeted Poverty Alleviation on Farmers' Multidimensional Poverty: The Intermediary Role of Migrant Workers. Economic and Management Review, 36(05): 27-41. 